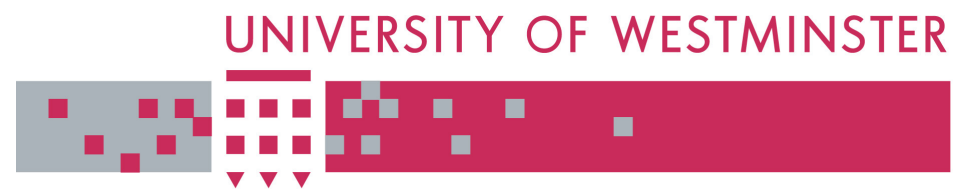

WestminsterResearch

http://www.wmin.ac.uk/westminsterresearch

\title{
Book review: McCance and Widdowson's the composition of foods - sixth summary edition.
}

\section{Claire E. Robertson}

At the time of publication Claire Robertson worked within the Department of Epidemiology \& Public Health, Imperial College, London. The author now works within the School of Biosciences, University of Westminster.

This is an electronic version of an article published in Nutrition Bulletin, 28 (1). pp. 81-83, March 2003. The definitive version is available at:

$\underline{\text { www.blackwell-synergy.com }}$

The WestminsterResearch online digital archive at the University of Westminster aims to make the research output of the University available to a wider audience. Copyright and Moral Rights remain with the authors and/or copyright owners. Users are permitted to download and/or print one copy for non-commercial private study or research. Further distribution and any use of material from within this archive for profit-making enterprises or for commercial gain is strictly forbidden.

Whilst further distribution of specific materials from within this archive is forbidden, you may freely distribute the URL of WestminsterResearch.

(http://www.wmin.ac.uk/westminsterresearch).

In case of abuse or copyright appearing without permission e-mail wattsn@wmin.ac.uk. 
McCance and Widdowson's The Composition of Foods - Sixth Edition.

\section{Claire E Robertson.}

Department of Epidemiology \& Public Health, Imperial College, Faculty of Medicine, Norfolk Place, LONDON W2 1PG.

\section{Correspondence:}

Dr Claire E Robertson, Department of Epidemiology \& Public Health, Imperial College, Faculty of Medicine, Norfolk Place, LONDON W2 1PG.

Tel: +44 207594 3301, Fax: +44 207402 2150, Email: c.robertson@ic.ac.uk

\section{Summary}

The sixth summary edition of McCance and Widdowson's The Composition of Foods Tables, compiled by the Food Standards Agency and the Institute of Food Research was recently published. The initial endeavours of Professor McCance and Dr Widdowson in the 1930's have been extensively developed, and this work composes a valuable reference tool for all those with an interest in UK food and nutrient consumption. This review considers the changes observed in the latest edition of these tables.

The sixth summary edition of McCance and Widdowson's The Composition of Foods incorporates product analysis data listed in the series of supplements published since the forth and fifth editions and some new, previously unpublished food composition data. These tables were first published in the 1930's, and have been extended to incorporate information on food items newly available on the retail market, to update the nutrient composition of traditional items as recipes change or fortifications are added, and simply to build on this information databank as new nutrients become of interest. Published food tables cannot hope to keep up with every change in the food retail market as these occur on an almost daily basis, however McCance and Widdowson's food composition tables compose an almost biblical reference tool for those with an interest in nutrition.

Uses for food composition tables differ according to the needs of each user-group (Schakel et al., 1997). Dietitians, for example, use them to advise patients on foods that should be consumed to reach specific nutrient goals. Researchers need them to convert dietary intake records to nutrient compositions, before attempting to correlate nutrient estimates calculated with health outcome data. Food manufacturers and retailers use them to assess the nutrient composition of their products, then convey this information via food labels. The ways in which this data source is used will determine the associated benefits and failings. Dietary assessments can only be as good as the food composition database and the coders, yet errors can also be introduced while calculating nutrient intakes due to inaccuracies in food tables and coding procedures or through poor interpretation of documentation (Bingham, 1987). No nutrient database can be entirely accurate as product compositions vary naturally and over time. Since published tables comprise a static data source, the quality of the database used must first be considered, then results obtained through its use should be interpreted on the basis of this. 
Given a users knowledge of the fifth edition of McCance and Widdowson's The Composition of Foods tables, the sixth edition appears to contain substantial amounts of new and updated material, much of which is taken from the series of detailed supplements (e.g. Chan et al., 1996; Holland et al., 1993; Tan et al., 1985). The introductory section of the book contains considerably more detail than previous editions. The history leading to their formation has been retained, however much of the other information provided has been extended. For example, the description of data sources and methods used to analyse foods to assess their nutrient content, explanations of how each nutrient is calculated and/or expressed, and the list of potential problem areas linked to the use of food composition tables have all been developed. The 24-page introduction is perhaps a section that might be overlooked by users not realising the task involved in the compilation of such food tables since the compositional data is usually the main reason for using this book, however it should be commended for its intrinsic worth. It provides a succinct synopsis of the methods used to analyse nutrient contents, sets a good foundation for the depth of information contained within the food tables and appendices which follow, and outlines the scope of the task of compiling and updating these food tables.

The aesthetic structure of the main tables has been improved in the sixth edition, with every second line of compositional data shaded to deter us from reading the nutrient values for the product above or below. The traditional order of the food data tables has been retained, however some new data on individual sugars (glucose, fructose, sucrose, maltose and lactose) has been added (in every section except meat and meat products) and the analysis of dietary fibre has been changed to measure only nonstarch polysaccharide (fibre was previously analysed using the Southgate and Englyst methods). Although new food items such as crème fraiche and fresh pasta have been added, only 47 more lines of data are contained in the sixth edition tables as unlike the fifth edition, only nutrient information for the 'edible' portion of a food is detailed here. Users can still obtain compositional information for food items estimated in quantities including the inedible matter (e.g. the bone in a lamb chop or the skin on a banana) through the use of the 'edible conversion factor' listed beside each food item. This will increase the amount of work involved for dietary investigators when converting weights of foods (estimated including the inedible portion) to nutrients consumed, and thus could increase the occurrence of calculation errors, however it has enabled a much greater proportion of available food items to be listed in the latest edition and in a concise format, preventing the summary edition of the McCance and Widdowson Food Tables from becoming a three book set!

A series of additional tables are also included in the sixth edition. These contain new nutrients of interest to nutrition-based professionals, including phytosterols (plant sterols distinct from cholesterol), an alternative method of measuring dietary fibre (the AOAC method, which includes lignin and resistant starch rather than only non starch polysaccharide), carotenoid fractions, vitamin $\mathrm{E}$ fractions and vitamin $\mathrm{K}_{1}$. These tables are incomplete in as far as they do not contain data for all food items contained in the main tables in this edition, however many of the main food sources are covered, and as the methods used to analyse their content are included in the introductory section, data might be expected to grow in future editions should their dietary concentration remain of interest. The appendix-held information illustrates how cooking and food preparation methods can alter nutrient composition and/or food 
weights; explains how inedible matter can be accounted for in nutrient calculations; lists recipes used to calculate composite meals nutrient contents, and links old food codes to new. The supplementary features of this sixth edition have allowed considerably more detail to be included, without adding pages of data to published food tables, by explaining how to calculate nutrient concentrations for foods consumed or reported in different formats, rather than doing the actual calculations.

A number of problems experienced following previous updates of food composition tables have been addressed in this edition. Food intake records collected in, for example, 1998 could only (up until now) have been coded using fifth edition food composition data if the McCance and Widdowson tables were being used in the analysis. This was published in 1993 (Holland et al., 1993) therefore the nutrient contents could be considered dated and researchers may wish to reanalyse records using a more recent edition of these food composition tables (Food Standards Agency, 2002). Recoding old food records using the newly produced sixth edition food codes would previously have required a complete re-code. The addition of index tables as an appendix however has enabled a linkage between new and old food codes. Foods with an unchanged composition are numbered using the suffix contained in each supplement edition (e.g. cereals and cereal products $=11$ ) and the original product code, and those which have been reanalysed have been given a new food code. This index can therefore be used to link old food codes to new, and thus has facilitated a more automated re-code of existing food records to facilitate a re-analysis of old records using more recent compositional data. The same consecutive method of numbering foods in the main tables has been upheld, thus, the efficient search facility has been retained while those familiar with the food codes used in the fifth edition can now link old and new codes easily.

The sixth edition of these tables is irreparably flawed in a number of areas. Published tables cannot hope to reflect every change observed in the food retail market as product compositions change frequently when ingredients become unavailable or manufacturers find new recipe combinations for example. All compositional data contained in these tables can be considered a good assessment of the products available at the time of analysis, however new food items or compositional changes in products may not be represented if they have occurred after the food tables have been published. Food items consumed may not match the nutrient composition for the closest food description contained in the tables as analyses are based only on some of the available foods of each type. If the product consumed is not one of the most popular of its kind, the nutrients listed for the food code in these tables may not be the best match we might hope for. Errors such as those mentioned here and variability caused by seasonal differences in soil quality or linked to the age of a food item (degeneration of starches to sugars are evident as a banana ripens for example), cannot be accounted for in food tables, however their effects should be taken into account by users of these tables. The latest edition of the McCance and Widdowson composition of foods tables contains many improvements, in content and in structure. The failings of any inactive list of food composition data are well known, and could compromise the quality of dietary data assessed using them, however McCance and Widdowson composition of foods tables will continue to be an irreplaceable handbook for all those who need or want to know about what is contained within food items consumed within the UK. 


\section{References}

Bingham, S.A. (1987) The dietary assessment of individuals; methods, accuracy, new techniques and recommendations. Nutrition Abstracts and Reviews (Series A) 57: 705-742.

Chan W., Brown J., Church S.M., \& Buss D.H. (1996) Meat Products and Dishes. Sixth Supplement to the Fifth Edition of McCance \& Widdowson's The Composition of Foods. The Royal Society of Chemistry \& Ministry of Agriculture, Fisheries and Food, Cambridge.

Food Standards Agency (2002) McCance and Widdowson's The Composition of Foods. Sixth Summary Edition. The Royal Society of Chemistry, Cambridge.

Holland B., Welch A.A., Unwin I.D., Buss D.H., Paul A.A., \& Southgate D.A.T. (1993) McCance and Widdowson's The Composition of Foods. Fifth Edition. The Royal Society of Chemistry \& Ministry of Agriculture, Fisheries and Food, Cambridge.

Holland B., Brown J., \& Buss D.H. (1993) Fish and Fish Products. Third Supplement to the Fifth Edition of McCance \& Widdowson's The Composition of Foods. The Royal Society of Chemistry \& Ministry of Agriculture, Fisheries and Food, Cambridge.

Schakel, S.F., Buzzard, M.I., and Gebhardt, S.E. (1997) Procedures for estimating nutrient values for food composition databases. Journal of Food Composition and Analysis 10, 102-114.

Tan S.P., Wenlock R.W., \& Buss D.H. (1985) Immigrant Foods. Second Supplement to the Fourth Edition of McCance \& Widdowson's The Composition of Foods. Her Majesty's Stationary Office \& Elsevier/North-Holland Biomedical Press, London, Amsterdam, New York, Oxford 